\title{
Smart Home Delivery E-Shopping cart to Facilitate Disable Individuals
}

\author{
J. A. D. C. A. Jayakody \\ Department of Information \\ Systems \& Engineering \\ Faculty of Computing \\ Sri Lanka Institute of \\ Information Technology
}

\author{
P. D. Kudagamage \\ Department of Information \\ Systems \& Engineering \\ Faculty of Computing \\ Sri Lanka Institute of \\ Information Technology
}

\author{
H. A. W. P. Madushanka \\ Department of Information \\ Systems \& Engineering \\ Faculty of Computing \\ Sri Lanka Institute of \\ Information Technology
}

\author{
S. S. Pathirana \\ Department of Information Systems \& Engineering \\ Faculty of Computing \\ Sri Lanka Institute of Information Technology
}

\author{
H. B. D. N. Dushanthi \\ Department of Information Systems \& Engineering \\ Faculty of Computing \\ Sri Lanka Institute of Information Technology
}

\begin{abstract}
In the light of providing a solution for the elderly and differently abled to obtain smart home delivery of essential household commodities, a brand new mobile application named "E-shopper" is introduced. In the present day context, the rapid escalation of the cost of living has become a very crucial factor and a challenge for every person. Thus, the authors decided to build a cross-platform mobile application to facilitate their needs and wants effectively and efficiently. In the system, the application decides the best supermarket to buy the specific item list provided by the customer by displaying automated customized preferences by analyzing the least total cost for the list of products. The application will show the nearest branch of the particular supermarket for the customer's location by using outdoor navigation. Moreover, a delivery method will also be provided by the application to make it more convinient for the customer. Since the increase in elderly and differently abled population becoming a crucial factor in the world; the authors decided to use voice method parallel to the normal mode (for regular customers) in the application. Three parties will involve in the e-system such as regular or differently abled clients, administrators and finally those who deliver. On the other hand, the delivery services will benefit through this system and their delivering companies will also be marketed. Therefore, this system introduces a brand new shopping concept for the customers in addition to the golden opportunity that other parties included in this system will have in boosting their revenue.
\end{abstract}

\section{Keywords}

Smart Home Delivery; Voice Recognition; Automated Preferences; Database Optimization and Clustering; Delivery Scheduling

\section{INTRODUCTION}

The rapid escalation of the elderly and differently abled population in the world is becoming a very critical factor [9]. Even though they will share a higher population of the society in the future, it will be tough for them to live alone and purchase their household necessities by visiting all the shops.
On the other hand, the increasing nature of cost of living is becoming a burning issue of the country and a challenge for the families around the world. In order to find the best quality product for the lowest price, customers will have to spend much time to search in every market around their area. Merely, checking from several media will not facilitate their requirements. Although most of the supermarkets display their product prices, it will not be possible to compare with every supermarket product prices. Sometimes, it is really hard to identify if some markets try to sell their products for the unfairly higher price by just visiting few markets. Therefore, it is not practical for the people who are caught up in the present day busy schedules of the world to find the best (least cost for the highest quality) product.

In the event of providing a solution to the issues discussed above, the developers will create a cross-platform mobile application through which the customers can include their list of commodities they need to buy. Furthermore, the application will display the customized preferences, automated according to the requirements of the specific customer by saving their precious time without wasting time in searching for daily needs. As the next step, those data will be sent to the database, and the total price to be spent to that entered item list will be automatically calculated for every supermarket in the application database. Likewise, the application will determine the supermarket with the least total price for the entered item list provided by the customer. Simultaneously, the application will show the nearest branch of the selected supermarket. The application will also suggest a delivery system by using machine language to make a delivery schedule for each order. Whenever, an order is placed; the deliverer gets a notification for the mobile and will deliver the items to that location from the selected supermarket. The destination to deliver will be shown in the navigation system provided through the app.

As the main target group of this app will be the elderly and differently abled customers, there will be a voice mode in the mobile application in addition to the regular customer mode. Therefore, from this request, even the differently abled individuals can place their orders and receive the item list by just staying at home by only using a smart mobile phone. 
The ultimate goal of this research is to develop a mobile application to facilitate people, especially differently-abled individuals to buy essential goods to make their day today life $\&$ activities very comfortable in an efficient \& effective manner. The overall outcome of this e-shopper mobile app is to provide a brand new marketing concept. This system will help to purchase day to day household necessities at the minimal cost which is possible, without visiting every supermarket and comparing the prices and availabilities.

- Create a voice recognition enabled application which facilitates differently abled individuals using machine learning techniques.

- Displaying Automated Preferences according to the specified customer using machine learning techniques.

- Find the minimum total bill and relevant super-market.

- Find the nearest supermarket according to the minimal aggregate bill via machine learning and data clustering mechanisms.

\section{LITERATURE REVIEW}

According to the Literature Survey, the history of relevant areas could be identified. Some people had created various shopping systems for differently abled people. They had created automated barcode reading systems, Automated Robot Carts etc. In the verge of online shopping processes, some people had created web sites through which the online purchases can be made just by logging into the website. Hence, the below-mentioned sample researches, pave a path to implement the app by providing a brief idea about relevant research areas.

Snap card is an online shopping website which allows the customers to select the supermarket and enter the nearest city manually from which the customers want to purchase particular products. Once the order is placed, an employer of the Snapcart will visit the supermarket preferred by the customer and handpick the products in the client list, and that person will deliver that item list to the customer's home [2].

Pick-Me is a mobile application which facilitates transport to customers. In the app, it will create a virtual circle on the Google map by making the location of the client as the center location of the circle. Therefore, when a customer request for a vehicle this application shows the vehicles located only in that prescribed virtual circle [1].

The Amazon is able to provide a voice recognition online shopping mobile application to gets products to your door step. When the customer says the item name it will search and provide the item and automatically added to cart.However, they were unable to provide products such as fruits, vegetables and dry foods [3].

Effectively utilizing the greater part of the accessible registering gadgets is a noteworthy issue for shifted processing frameworks. Creators had proposed a scheduler that chooses the executing gadget after earlier preparing, in view of the span of the info information. The article additionally contains the plots and time qualities that exhibits change in general execution time contingent upon the information. The program modules were produced in $\mathrm{C}++$ utilizing CUDA libraries [5].

The utilization of GPS in open air confinement is a significant open arrangement in huge situations. Stefano Panzieri, Federica Pascucci, and Giovanni Ulivi, had built up a limitation calculation in view of Kalman sifting that tries to utilize data originating from a modest single GPS with inertial information and guide based information. The calculation could deliver unsurprising arrangement for the robot that can effectively remark in a route framework [6].

In view of creators' inclusion and entanglements they propose a model for gathering and handling client conduct information. They were available a few after effects of disconnected tests on genuine creation information. They demonstrated that simple information on clients' conduct were adequate for development of forecast of client inclination [7].

Creators recommended a proposition of a webshop with client preference looking - "Pref-Shop". It was made possible by running a typical web shop with new facilities were yet to be added [8].

\section{PROBLEM IDENTIFICATION}

\subsection{Problem Statements}

- How effectively the normal environment and relevant technologies are used to provide a SMART solution for differently abled individuals with assistive technology?

- How effectively the standards and relevant techniques are used to find a relevant requirement in supermarket process with clustering?

- How effectively is the environment used to get the best package and predict preferences with data science?

- How effectively are the present techniques utilized to provide good delivery service with machine learning?

\subsection{Research Gap Analysis}

According to the literature review, although previous processes had the e-shopping concept, they did not have an all in one solution for differently abled individuals to compare the total prices in selecting the cheapest shop for relevant purchases with door step delivery. This will be a very good benefit as people do not have to walk around to search or order goods as they can get it delivered to their home. This emphasizes the "All in One "concept.

The blind people will be the major focus group among the differently abled in this app. For them up to present, online shopping means such as E-commerce or M-Commerce is not very popular due to their physical and natural disabilities. Therefore, authors are willing to a create system which uses assistive technology to facilitate such differently-abled individuals.

\subsection{Main Research Areas}

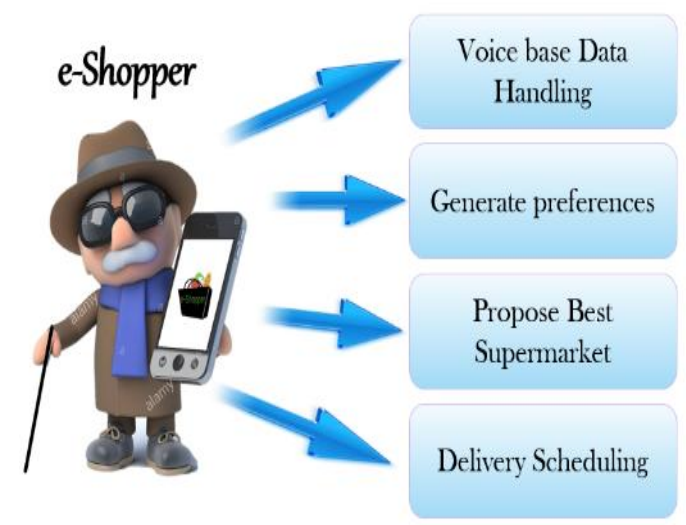

Figure 1: Main Processes 


\section{System Overview for Proposed Solution}

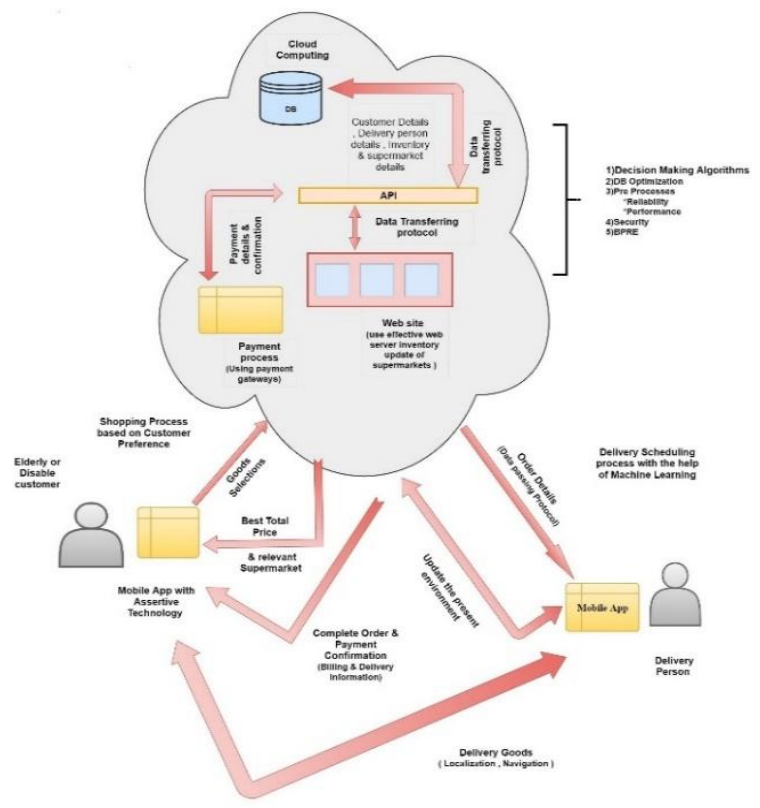

Figure 2: Proposed System Overview

\section{OVERVIEW OF MAIN RESEARCH AREAS}

\subsection{Voice Recognition System through Assistive Technology and Machine} Learning

- Customer registration
process
collecting process $\rightarrow \begin{aligned} & \text { - Customer account } \\ & \text { creation component } \\ & \text { - Train data set with } \\ & \text { ontology component } \\ & \text { Voice guidance } \\ & \text { component }\end{aligned} \rightarrow \longrightarrow \begin{aligned} & 0 \text { Create } \\ & \text { customer } \\ & \text { database } \\ & - \text { Create order } \\ & \text { list }\end{aligned}$

Figure 3: Voice recognition \& customer handling System

When a user enters a product through voice, it may have been not the exact word which is included in the database, but it is trained, to give output as the authors need. The application has been specially trained according to the entire included item list via a specially configured algorithm using ontology technology. For that, several voice commands have been entered and trained for one word.

\section{Ontology Process :}

Database $\rightarrow$ Beet, Carrot, Chicken, Grapes, Rice, Chocolate

User Input $\rightarrow$ Chicken, Rice, Parrot, Beat, Capes

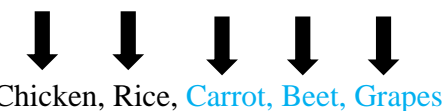

App Output $\rightarrow$ Chicken, Rice, Carrot, Beet, Grapes

\subsubsection{Research Findings}

In the course of voice recognition task, ONTOLOGY algorithm was used togreater extent. Whenever, a specific customer enters a particular product name, to assure a successful ordering process, the system should identify the matching product name in the application database with the entered product type. In this scenario, the voice input of the customer may not always be clear to the system. So, the ontology algorithm comes to assist the system in identifying the correct matching word from the supermarket database.

During the implementation process, it was revealed that, the system fails to identify the correct words as intended by the specific customers due to various reasons such as; environmental noise, quality of the microphone avalable in the smartphone as well as the different accents in pronouncing words. The environmental noise can become a greater hindrance in the process of input of relevant commodity names. On the other hand, less quality microphones in smartphones of the users can also obstruct the input of correct product names.

Finally, the different accent styles of different type of people can result in failure to identify the intended commodity names. The Ontology algorithm will overcome all of these issues by assisting the system to find the most matching word fed to the system.

\subsection{Automated Customized Preferences through Machine Learning}

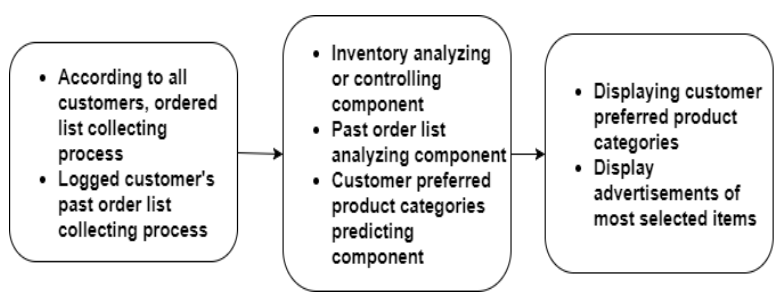

Figure 4: Automated Preferences Displaying System

Predicting preferences process, authors will use hypothesis and probability concepts. In here, machine learning techniques and concepts will give great support to predict customized preferences which related to a particular customer as well as a large number of the customer base. Therefore Naive Bayes theorem will be used for predictions with the help of collected data. Authors also get the support of arrays, index concepts to identify patterns of customer taste.

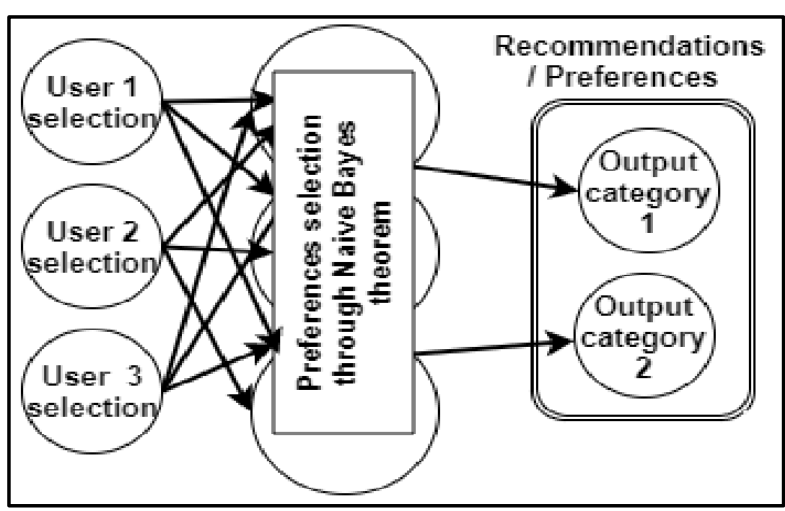

Figure 5: Automated Preferences Displaying System with sample algorithm

Learning: based on frequency counts in the dataset

Estimate allp $(\boldsymbol{a} j \mid y) \forall \boldsymbol{y} \in \boldsymbol{Y}, \forall \boldsymbol{a j}$

Classification: Ex.

Ynew $=\operatorname{argmax} y \in Y p(y) \prod_{j} p(a j \mid y)$ 


\subsubsection{Research Finding}

The tautological Bayesian Machine Learning algorithm is the Naive Bayes classifier, which utilizes Bayes' Rule with the strong independence assumption that features of the dataset are conditionally independent of each other, given that authors know the class of data, they can apply this to spam filtering.

In spam filtering, process would like to classify messages as spam or non-spam. Authors first learn a decision rule, then apply this rule to new incoming messages. The essence of Naive Bayes is in the model creation process. To model the probability of a word, "w", Naive Bayes makes the important assumption that all words, denoted by the vector are conditionally independent the class of the message (spam or non-spam). That is, if the message is spam, the word "Nigerian" and the word "Prince" are conditionally independent. This classifier is aptly named - it is naive to assume this conditional independence.

However, given this conditional independence, authors can write the probability of a message being spam as

$$
\mathrm{P}\left(\mathrm{X}_{1} \ldots \mathrm{X}_{\mathrm{n}} \mid \mathrm{Y}\right)=\prod_{i=1}^{n} p(X i \mid Y)
$$

The conditional independence assumption gives a very elegant formula above that at its core, is a repeated application of Bayes' Rule, for each word in the message.

\subsection{Database Optimization and Clustering}

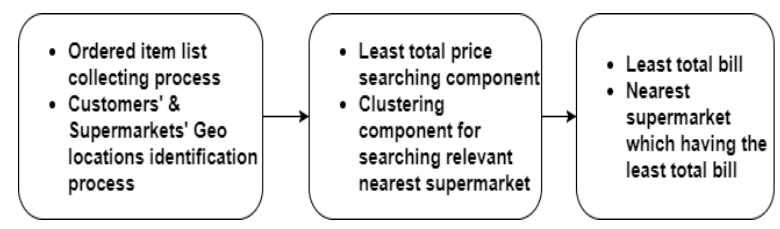

Figure 6: Database optimization \& Clustering System

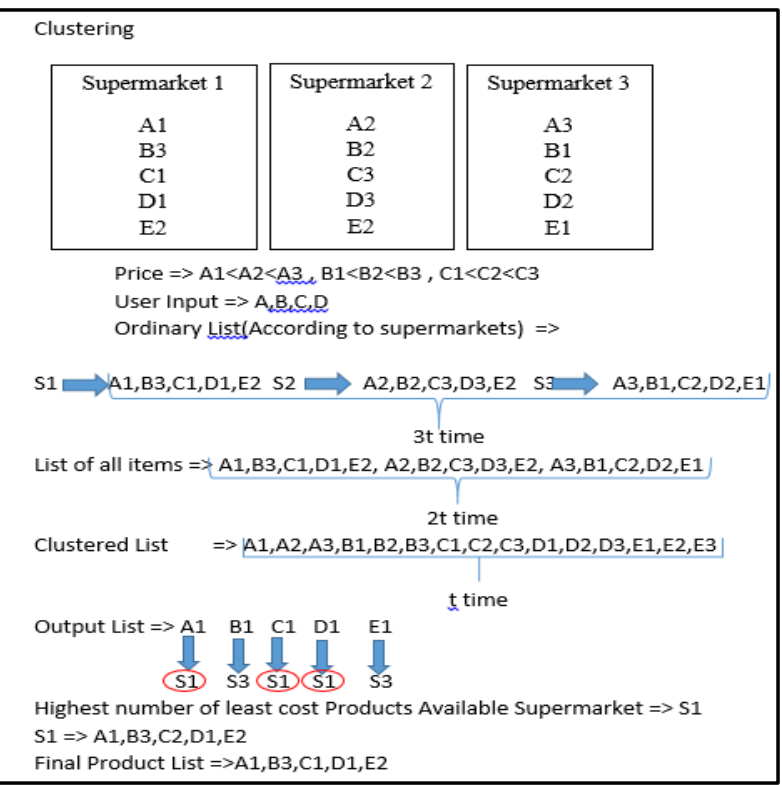

Figure 7: Clustering Process

The most special thing about this marketing structure is to identify the best supermarket in different product lists at different time duration. So that, this supermarket prediction is based on few parameters.
1. Product list price

2. Product list entered date

3. Rider's location

The customer can enter one specific product list, so the product list will be compared with the specific tables in the database to check the product list prices in every supermarket to find the best supermarket. Hence there is a possibility for not getting the same output for another product list because of having a different total price. Product list entered date is also a considerable fact when predicting the best supermarket while offers, discounts or some other price variations can affect the product prices. Aftermath, the exact branch of the predicted supermarket will be retrieved considering Rider's nearest branch.

In order to predict the best supermarket, the customer should enter a product list for the E-Shopper system. That product list goes through all the supermarkets to calculate the lowest priced supermarket. For that to be a success, authors have used an optimized data storing mechanism with an effective clustering method.

\subsubsection{Research Findings}

In the process of predicting the best supermarket, Generic Machine learning algorithms were used to make the system more productive to the customers. One algorithm was used to establish and enhance database optimization so that the customers get the correct output (Clustering Algorithm).

From the defined algorithm, the system chooses the best supermarket not by going through every table of the supermarkets but by going through one table which the products are inserted in a sorted order according to the product prices. So the system can search for the least cost product from each supermarket at the first time the system finds the product name.

Another machine learning algorithm was defined by the authors to test the implementation of the above mechanism. Hence, the error checking algorithm was introduced by the author.

The other algorithm checks whether right supermarket is chosen from the first algorithm. This algorithm is configured in the E-Shopper system itself to produce an output with very low percentage of errors.

\subsection{Delivery Scheduling and Navigation with the help of Genetic Algorithm}
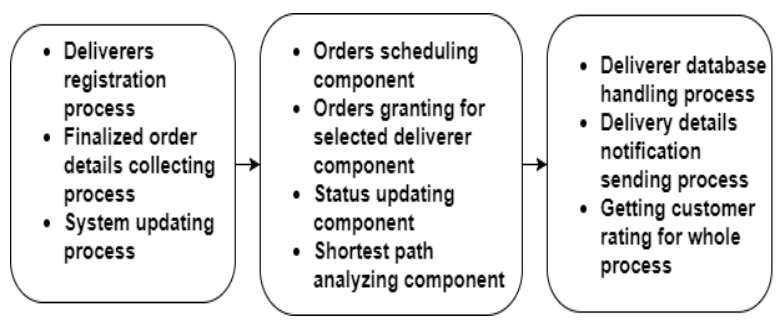

Figure 8: Delivery scheduling management \& Shortest Path analyzing System

Delivery scheduling process has some conditions to select a particular deliverer. They specify a particular area covering the selected branch, availability of registered deliverers, amount of cash in hand and the number of hires that a particular deliverer gets. Authors created a genetic algorithm 
with these and applied it to different priority levels.In analyzing the shortest path according to the destination to find the best route, some algorithms and concepts in machine learning, such as fitness functions in Traveling Salesman Problem, Dijkstra algorithm and Genetic algorithm were used. All of these were used to optimise the delivery process.

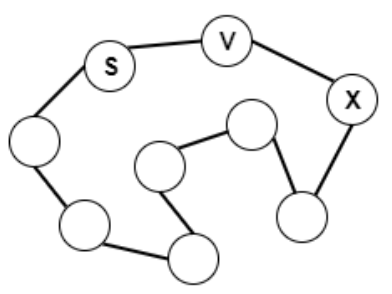

$f(S, V)=$ Length of a shortest route starting at $S$ ending at $V$ and visiting all nodes in $\mathrm{S}$

$X € S$

$(x, v) € E$

Figure 9: Sample shortest path analyzing algorithm

$$
\begin{aligned}
& f(s, v)=\min \int(s(x), x)+C x v \\
& \text { Initial Condition }: f(\oint, s)=0 \\
& \text { Solution }: \int(V\{s\}, s)
\end{aligned}
$$

\subsubsection{Research Findings}

When considering the whole process of DPMM, it has two main functions. Those are Delivery Scheduling and the Navigation. Since whole backend process should be done through the system automatically, the authors have to consider some conditions in gaining the correct relevant outputs.

Delivery scheduling function has some conditions. Such as

$\circ$ Deliverer should be registered in the application

- Deliverer should be online in the application

- Deliverer should be available near the selected supermarket branch

- According to the system should have minimum number of hires had got previously

- According to the system details, deliverer's total cash in hand should be less than or equal to Rs.3000

As a summary, tables in the testing evaluation section will show the relationship of the condition to select a deliverer. i.e applying priorities and without applying priorities. It will show when the conditions got changed how automatically select a deliverer from the algorithm as the output.

In this situation authors had to consider many real scenarios. As the example, if developers consider about the no. of hires that a deliverer gets rather than the cash in hand, it is not practical because some deliverers can collect maximum cash amount by less no.of hires and some of other deliverers can collect maximum cash amount by large no. of hires. Therefore, developers had to give priority to the cash in hand amount when selecting a deliverer.

Next function part of the DPMM process is the Navigation. In this function, deliverer will be navigated to the nearest selected supermarket branch. For that, first one deliverer should be selected. Therefore scheduling and navigation functions are inter related to fulfill the target of DPMM. In here authors had check many theories, concepts as well as the algorithms to find the optimized best path.

Developers had checked the Travelling Salesman problem concept in machine learning but in the suggested full system, it does not supply previous orders as a collection. With the help of the concept of routing algorithms specially Dijkstra algorithm and Triangular method to determine the best minimum distance and the route which should deliver follow, developers used some parameters, specially, selected supermarket branches' longitude and latitude, destination's longitude and latitude as well as the deliverer's current longitude and latitude.Here they basically used GPS Technology to improve the process and to gain clear parameters. Finally they created a genetic algorithm to find the correct deliverer as well as the navigation routes.

Therefore, they were able to check the minimum distance between selected supermarket branch and the deliverer. If other conditions matches, the particular deliverer will get the chance. But if other conditions do not match, they again check the next nearest minimum distance between the available deliverer and the selected supermarket. Likewise this process will go forward until a correct deliverer via the algorithm with those parameters is selected as the automated backend processes.Finally all the relevant details of the selected deliverer and granted orders can be viewed by the admin panel through the website at any time.

\section{TESTING AND EVALUATION}

Table 1 : Testing Voice Recognition

\begin{tabular}{|l|c|c|c|c|c|c|c|c|}
\hline \multirow{2}{*}{$\begin{array}{l}\text { Sample } \\
\text { words }\end{array}$} & \multicolumn{4}{|l|}{ Recognized } & \multicolumn{4}{|c|}{ Not Recognized } \\
\cline { 2 - 9 } & T1 & T2 & T3 & T4 & T1 & T2 & T3 & $\begin{array}{l}\text { T } \\
4\end{array}$ \\
\hline Nadu Rice & - & - & - & $\checkmark$ & $\square$ & $\square$ & $\square$ & - \\
\hline Carrot & $\checkmark$ & $\checkmark$ & $\checkmark$ & $\checkmark$ & - & - & - & - \\
\hline Toothbrush & - & $\checkmark$ & $\checkmark$ & $\checkmark$ & $\square$ & - & - & - \\
\hline $\begin{array}{l}\text { Samba } \\
\text { Rice }\end{array}$ & - & - & $\checkmark$ & $\checkmark$ & $\square$ & $\square$ & - & - \\
\hline Noodles & - & $\checkmark$ & $\checkmark$ & $\checkmark$ & $\square$ & $\square$ & - & - \\
\hline Sugar & - & - & - & $\checkmark$ & $\square$ & $\square$ & $\square$ & - \\
\hline Salt & - & - & - & $\checkmark$ & $\square$ & $\square$ & $\square$ & - \\
\hline Beetroot & $\checkmark$ & $\checkmark$ & $\checkmark$ & $\checkmark$ & - & - & - & - \\
\hline Cabbages & - & - & - & $\checkmark$ & $\square$ & $\square$ & $\square$ & - \\
\hline
\end{tabular}

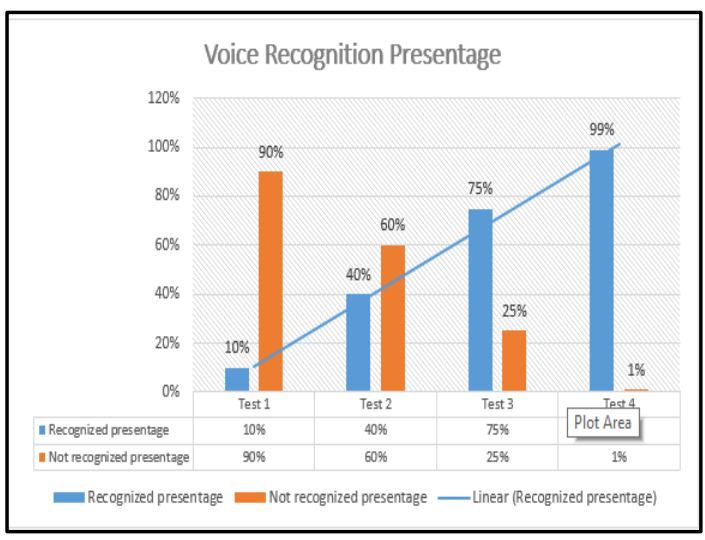

Figure 10: Test result of voice recognition

Table 2 : Testing Delivery scheduling conditions - When applying priorities

\begin{tabular}{|l|c|c|c|c|c|c|c|c|}
\hline \multicolumn{10}{|l|}{ When applying priorities for conditions } \\
\hline $\begin{array}{l}\text { Availability(with } \\
\text { in the selected } \\
\text { area) }\end{array}$ & $\checkmark$ & $\checkmark$ & $\checkmark$ & $\checkmark$ & - & - & - & - \\
\hline $\begin{array}{l}\text { Availability(out } \\
\text { of the selected } \\
\text { area) }\end{array}$ & - & - & - & - & $\checkmark$ & $\checkmark$ & $\checkmark$ & $\checkmark$ \\
\hline No. of & $\checkmark$ & $\checkmark$ & $\checkmark$ & X & $\checkmark$ & $\checkmark$ & $\checkmark$ & X \\
\hline
\end{tabular}




\begin{tabular}{|l|c|c|c|c|c|c|c|c|}
\hline Hires(H<5) & & & & & & & & \\
\hline $\begin{array}{l}\text { Having lowest } \\
\text { no. of hires }\end{array}$ & $\checkmark$ & $\checkmark$ & X & - & $\checkmark$ & $\checkmark$ & X & - \\
\hline Cash in Hand & $\checkmark$ & X & - & - & $\checkmark$ & X & - & - \\
\hline Selected Vehicle & A & B & C & D & E & F & G & H \\
\hline $\begin{array}{l}\text { Order granting } \\
\text { probability }\end{array}$ & $\begin{array}{c}1^{\text {s }} \\
\text { t }\end{array}$ & & & & $\begin{array}{c}2 \\
\text { nd }\end{array}$ & & & \\
\hline
\end{tabular}

Table 3 : Testing Delivery scheduling conditions - When haven't applying priorities for conditions

\begin{tabular}{|c|c|c|c|c|c|c|c|c|c|c|}
\hline \multicolumn{11}{|c|}{ When there is no priorities for conditions } \\
\hline $\begin{array}{l}\text { Availability } \\
\text { (within the } \\
\text { selected } \\
\text { area) }\end{array}$ & $\checkmark$ & $\checkmark$ & $\checkmark$ & $\checkmark$ & $\checkmark$ & - & - & - & - & \\
\hline $\begin{array}{l}\text { Availability } \\
\text { (out of the } \\
\text { selected } \\
\text { area) }\end{array}$ & - & - & - & - & - & $\checkmark$ & $\checkmark$ & $\checkmark$ & $\checkmark$ & \\
\hline $\begin{array}{l}\text { No. of } \\
\text { Hires }(H<5)\end{array}$ & $\checkmark$ & $\checkmark$ & $\checkmark$ & $\mathrm{X}$ & $\mathrm{X}$ & $\checkmark$ & $\checkmark$ & $\checkmark$ & $\checkmark$ & $\mathrm{X}$ \\
\hline $\begin{array}{l}\text { Having } \\
\text { lowest no. } \\
\text { of hires }\end{array}$ & $\checkmark$ & $\checkmark$ & $\mathrm{X}$ & $X$ & $X$ & $\checkmark$ & $\checkmark$ & $X$ & $X$ & $\mathrm{X}$ \\
\hline $\begin{array}{l}\text { Cash in } \\
\text { Hand }\end{array}$ & $\checkmark$ & $\mathrm{X}$ & $\checkmark$ & $\checkmark$ & $\mathrm{X}$ & $\checkmark$ & $X$ & $\checkmark$ & $X$ & $\checkmark$ \\
\hline $\begin{array}{l}\text { Selected } \\
\text { Vehicle }\end{array}$ & A & B & $\mathrm{C}$ & $\mathrm{D}$ & I & $\mathrm{E}$ & $\mathrm{F}$ & $\mathrm{G}$ & $\mathrm{H}$ & $\mathrm{J}$ \\
\hline $\begin{array}{l}\text { Order } \\
\text { granting } \\
\text { probability }\end{array}$ & $\begin{array}{l}1 \\
\mathrm{~s} \\
\mathrm{t}\end{array}$ & & & & & $\underset{\text { nd }}{2}$ & & & & \\
\hline
\end{tabular}

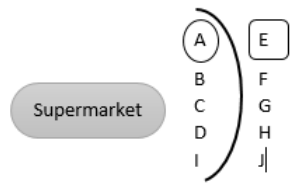

Figure 11: Sample situation

Testing: Taking the product item with low price variations.

Table 4: Sample Supermarkets

\begin{tabular}{|l|l|l|}
\hline Sx & Sy & Sz \\
\hline A2 & A1 & A3 \\
\hline B3 & B2 & B1 \\
\hline C2 & C1 & C3 \\
\hline D2 & D1 & D3 \\
\hline E2 & E3 & E1 \\
\hline
\end{tabular}

$$
\text { User Inputs } \rightarrow \mathrm{A}, \mathrm{B}, \mathrm{C}, \mathrm{D}, \mathrm{E}
$$
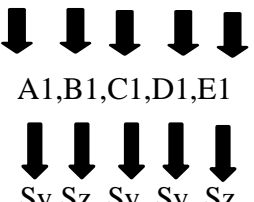

So, best supermarket (According to the algorithm) $=\mathrm{Sy}$

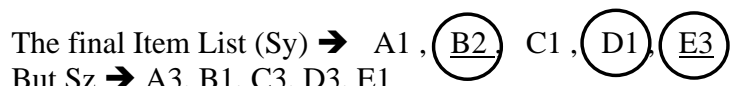

But $\mathrm{Sz} \rightarrow \mathrm{A} 3, \underline{\mathrm{B} 1}, \mathrm{C} 3, \mathrm{D} 3, \underline{\mathrm{E} 1}$

Take price variation:

$\mathrm{B} 2-\mathrm{B} 1=\mathrm{a}, \quad \mathrm{E} 3-\mathrm{E} 1=\mathrm{b}, \quad \mathrm{A} 3-\mathrm{A} 1=\mathrm{c}, \quad \mathrm{C} 3-\mathrm{C} 1=\mathrm{d}, \quad \mathrm{D} 3-\mathrm{D} 1=\mathrm{e}$ If $\mathrm{a}+\mathrm{b}>\mathrm{c}+\mathrm{d}+\mathrm{e}, \quad$ then $\mathrm{Sz}<\mathrm{Sy}$
Table 5: Test result of price variations

\begin{tabular}{|l|l|l|}
\hline \multicolumn{1}{|c|}{ Sy } & \multicolumn{1}{c|}{ Sz } & \multicolumn{1}{c|}{ Price variation } \\
\hline $\mathrm{A} 1=50$ & $\mathrm{~A} 3=58$ & $\mathrm{c}=8$ \\
\hline $\mathrm{B} 2=75$ & $\mathrm{~B} 1=50$ & $\mathrm{a}=25$ \\
\hline $\mathrm{C} 1=68$ & $\mathrm{C} 3=70$ & $\mathrm{~d}=2$ \\
\hline $\mathrm{D} 1=90$ & $\mathrm{D} 3=100$ & $\mathrm{e}=10$ \\
\hline $\mathrm{E} 2=90$ & $\mathrm{E} 1=72$ & $\mathrm{~b}=18$ \\
\hline Sy $=373$ & $\mathrm{Sz}=350$ & $\begin{array}{l}\mathrm{a}+\mathrm{b}=43, \\
\mathrm{c}+\mathrm{d}+\mathrm{e}=20\end{array}$ \\
\hline
\end{tabular}

Table 6: Test result of success of product lists Success Rate : $70 \%$

\begin{tabular}{|l|c|c|}
\hline \multicolumn{1}{|c|}{ Test } & Success & Fail \\
\hline Product list 1 & $\checkmark$ & \\
\hline Product list 2 & $\checkmark$ & \\
\hline Product list 3 & $\checkmark$ & \\
\hline Product list 4 & & $\checkmark$ \\
\hline Product list 5 & $\checkmark$ & \\
\hline Product list 6 & & $\checkmark$ \\
\hline Product list 7 & & $\checkmark$ \\
\hline Product list 8 & $\checkmark$ & \\
\hline Product list 9 & $\checkmark$ & \\
\hline Product list 10 & $\checkmark$ & \\
\hline
\end{tabular}

\begin{tabular}{|c|c|c|c|c|}
\hline \multirow{2}{*}{ Categories } & \multirow{2}{*}{$\begin{array}{l}\text { Used } \\
\text { perce } \\
\text { ntage }\end{array}$} & \multicolumn{2}{|c|}{$\begin{array}{l}\text { Most used item in } \\
\text { category }\end{array}$} & \multirow[t]{2}{*}{$\begin{array}{l}\text { Predic } \\
\text { tion }\end{array}$} \\
\hline & & Item & $\begin{array}{l}\text { Proba } \\
\text { bility }\end{array}$ & \\
\hline Beverages & 8 & Tea & 0.12 & \multirow{9}{*}{$\begin{array}{c}\text { Book } \\
\rightarrow \\
\text { Station } \\
\text { ary }\end{array}$} \\
\hline Cosmetics & 2.5 & Toothpaste & 0.05 & \\
\hline Dry Foods & 19 & Rice & 0.15 & \\
\hline Fruits & 12 & Apple & 0.03 & \\
\hline Meat & 6 & Chicken & 0.20 & \\
\hline Spices & 9 & Pepper & 0.04 & \\
\hline Stationary & 18 & Book & 0.30 & \\
\hline Sweet & 10 & Ice Cream & 0.10 & \\
\hline Vegetables & 15.5 & Carrot & 0.01 & \\
\hline
\end{tabular}

Table 7: Test result of preferences - Test 1 for Prediction

\begin{tabular}{|c|c|c|c|c|}
\hline \multirow{2}{*}{$\begin{array}{l}\text { Cat } \\
\text { ego } \\
\text { ries }\end{array}$} & \multirow{2}{*}{$\begin{array}{l}\text { Used } \\
\text { perce } \\
\text { ntage }\end{array}$} & \multicolumn{2}{|c|}{$\begin{array}{l}\text { Most used item in } \\
\text { category }\end{array}$} & \multirow[t]{2}{*}{$\begin{array}{l}\text { Preferenc } \\
\text { e }\end{array}$} \\
\hline & & Item & Probability & \\
\hline 1 & 8 & Beer & 0.10 & \multirow{9}{*}{$\begin{array}{c}\text { (Accordin } \\
\text { g to single } \\
\text { person } \\
\text { preference } \\
\text { probabilit } \\
\text { y) } \\
18 * 0.5= \\
\text { highest } \\
\text { Rice } \rightarrow \\
\text { Dry foods }\end{array}$} \\
\hline 2 & 5 & Shampoo & 0.02 & \\
\hline 3 & 18 & Rice & 0.50 & \\
\hline 4 & 13 & $\begin{array}{l}\text { Pineappl } \\
\mathrm{e}\end{array}$ & 0.01 & \\
\hline 5 & 8 & Egg & 0.04 & \\
\hline 6 & 10 & Ginger & 0.03 & \\
\hline 7 & 12 & Pen & 0.05 & \\
\hline 8 & 12 & $\begin{array}{l}\text { Chocolat } \\
\mathrm{e}\end{array}$ & 0.20 & \\
\hline 9 & 16 & Cabbage & 0.05 & \\
\hline
\end{tabular}

Table 8: Test result of preferences - Test 2 for preferences

\section{DISCUSSION AND CONCLUSION}

The development of technology has been affecting and playing significant roles in changing the lifestyle of people. The concept of simple shopping process has also been 
changing into smart online shopping concept, and the concept of ordinary shopping process has changed drastically over the last decade. However, the advancement of technology has played a major role in the development of negative aspects. It has increased the risk in security and health.

However, this paper gives a basic idea of the project named as Smart Home Delivery E-Shopping Cart to Facilitate Differently abled Individuals. The project presents how eshopping process works especially for differently abled individuals using Android phone/tab. The project is based on Android platform. This platform is frequently used Opensource, and it will be very cost effective. This consisted of an android application which can operate mainly in Voice mode (for vision impaired people) and Normal mode (for the general usage).

The whole project consists of 4 main subsystems, they are,

1. Voice Recognition System with the help of Machine Learning techniques.

2. Automated Customized Preferences Displaying System according to the logged customer.

3. Database Optimization and Clustering Process via Machine Learning techniques.

4. Delivery Scheduling and Shortest path analysis system.

By integrating all the above components, the authors were able to produce a mobile application which uses voice recognition, intelligent enough to determine the best supermarket according to the customer preferred product list and finally adding optimal delivery service which could be shaped into a new business model.

\subsection{Future Work}

Far beyond the present day application, it is planned to build a cross-platform system that can be deployed on various platforms like iOS. Although created application addresses only a selected group of users and authors can enhance it to cover the entire country. Authors can join with a huge marketplace like John Keels to enhance the product as an essential process of the country. It can also be extended to high priced items by implementing a reasonable \& rational equation to calculate the best-priced supermarket with those products. Authors could also consider the quality ratings of every product from user feedback to determine the best supermarket.

\section{ACKNOWLEDGEMENT}

Research is powered and supported by the Sri Lanka Institute of Information Technology.

\section{REFERENCES}

[1] "Pickme | Faster. Safer. Smarter". Pickme.lk. N.p., 2017. Web. 3 May 2017. [Online]. Available:http://pickme.lk/. [Accessed: 03- May- 2017].

[2] "Snapcart - Groceries to your door", Snapcart.lk, 2017. [Online]. Available: http://snapcart.lk/. [Accessed: 03May- 2017].

[3] "10 best shopping apps for Android", Android Authority, 2017. [Online]. Available: http:// www.androidauthority.com/best-android-shopping-apps544784/. [Accessed: 03- May- 2017].

[4] Vladimir Kulyukin, Aliasgar Kutiyanawala, "Accessible
Shopping Systems for Blind and Visually Impaired Individuals: Design Requirements and the State of the Art" [online] Available at https://www.researchgate.net/publication/228366395 Accessible_Shopping_Systems_for_Blind_and_Visually _Impaired_Individuals_Design_Requirements_and_the_ State_of_the_Art [Accessed 12 Aug. 2017].

[5] D.A. Shulga1, A.A. Kapustin, A.A. Kozlov, A.A Kozyrev, M.M. Rovnyagin, Ieeexplore.ieee.org. (2017).The scheduling based on machine learning for heterogeneous CPU/GPU systems - IEEE Xplore Document. [online] Available at: http://ieeexplore.ieee.org/document/7448189/?reload=tru e [Accessed 12 Aug. 2017].

[6] Stefano Panzieri, Federica Pascucci, and Giovanni Ulivi, Ieeexplore.ieee.org. (2017). An outdoor navigation system using GPS and inertial platform - IEEE Xplore Document. [online] Available at: http://ieeexplore.ieee.org/document/1011250/ [Accessed 12 Aug. 2017].

[7] Ieeexplore.ieee.org. (2017). e-shop user preferences via theuserbehavior - IEEE Xplore Document. [online] Availableat:http://ieeexplore.ieee.org/document/7509048 / [Accessed 5 Aug. 2017]

[8] Ieeexplore.ieee.org. (2017). Pref Shop A Web Shop with User Preference Search Capabilities - IEEE Xplore Document. [online] Available at: http://ieeexplore.ieee.org/document/5615768/ [Accessed 5 Aug. 2017].

[9] WHO, 2016, Visual impairment and blindness. [Online]. Available:http://www.who.int/mediacentre/factsheets/fs2 82/en/[Accessed 26-Apr-2017].

[10] Glaubius, R., Tidwell, T., Gill, C. and Smart, W. (2017). Real -Time Scheduling via Reinforcement Learning. [online]Arxiv.org. Available at: https://arxiv.org/abs/1203.3481 [Accessed 12 Aug. 2017].

[11] Terry L. Childers, Carol Kaufman-Scarborough, "Expanding opportunities for online shoppers with disabilities" Journal of Business Research 62 (2009) 572-578, Available Online, [Accessed March 2017].

[12] Rahul Bhoyar, Nitin Chopde, G.H. Raisoni, "Cloud Computing:Service models, Types, Database and issues", Available online,International Journal of Advanced Research in ComputerScience and Software Engineering - Volume 3, Issue 3, March2013 ISSN: 2277 128X, www.ijarcsse.com, [Accessed March 2017].

[13] "Google Maps Draw Route between two points using Google Directions in Google Map Android API V2", Android tutorials for hassle-free androiddevelopment and programming, [Online].Available:https://www.androidtutorialpoint.com /intermediate/google-maps-draw-path-twopoints- usinggoogle-directions-google-map-android-api-v2/.

[Accessed: 04- May- 2017]

[14] A. Rajpurohit, "Why Azure ML is the Next Big Thing for Machine Learning?", Kdnuggets.com, 2017. [Online]. Available: http://www.kdnuggets.com/2014/11/microsoft-azuremachine-learning.html. [Accessed: 26- Apr- 2017]. 
International Journal of Computer Applications (0975 - 8887)

Volume 180 - No.6, December 2017

[15] Ieeexplore.ieee.org. (2017). Evaluation of an online shopping system under Preferences and Constraints IEEE Xplore Document. [online] Available at: http://ieeexplore.ieee.org/document/6900974/ [Accessed 5 Aug. 2017].
[16] Ieeexplore.ieee.org. (2017). A measurement study on Amazon wishlist and its privacy exposure - IEEE Xplore Document.[online] Available at:

http://ieeexplore.ieee.org/document/7996684/[Accessed5 Aug.2017 